\section{American School Buildings}

ScHoor building problems in the United States have assumed such importance that a National Advisory Council has been organized under the auspices of the Office of Education, Washington, at the request of State superintendents and commissioners of education. At the Council's first conference it was determined to begin with a study of the "functional planning of elementary school buildings", and a report on this subject has been published by the United States Government Printing Office (pp. 84, 25 cents). The report, which is illustrated with numerous photographs, floor plans and charts, shows, among other things, that the elementary school curriculum is changing in ways which radically affect the planning of buildings, and that costs depend largely on the extent to which school work is organized so as to get a simultaneous, balanced use of all facilities. Taxpayers often protest against the excessive cost of providing for the numerous additions to the traditional "three Rs" demanded by the modern elementary school curriculum : music, art, science, crafts, training for leisure, physical culture, play, etc. The report claims that, by the adoption of the so-called 'platoon' system, accommodation for all these activities can be provided without extra cost. Under this system, the classes are all duplicated, and while one set occupies the 'home rooms' the other set uses the rooms set apart for special activities, and vice versa.

\section{Reading Administratively}

A GENERAL administration course of reading has been drawn up by Mr. W. R. Dunlop, 57 Gordon Square, London, W.C.1., designed to introduce the idea of reading administratively. While the course is intended primarily for those holding administrative positions, it has a cultural value and aims at serving as a practical form of education for citizenship, including membership, not only of a country or nation but also of businesses, services and institutions. It is intended to provide standards for criticism, imitation and inspiration. Utilizing material of administrative interest to be found in general as well as specialized works and including fiction and poetry, the course should give a general insight into how man governs in different fields and at different levels in the complex hierarchies of administrative control. While there is no time limit it is suggested that, reading eight hours a week, the recommended literature could be studied adequately in six to nine months, after which the practical reader will begin to specialize. Tuitional assistance is given by post in the form of instruction regarding the meaning and principles of administration and what to look for, more detailed treatment of examples, criticism of readers' notes and the like.

\section{Aquarist and Pond-keeper}

We are glad to note that the Aquarist and Pondkeeper is to be published monthly in future instead of every two months. Ever since it was founded by the late Mr. A. E. Hodge, amateur aquarists have had cause to be grateful for its helpful articles on the many aspects of their hobby. These articles have, on the whole, reached a high standard without being too technical. The illustrations, too, have generally been good, some of the photographs of living fishes taken by Mr. W. S. Pitt, for example, deserving special mention. There have, in addition, been regular articles on reptiles and amphibians and their management in vivaria; these must have had considerable effect in popularizing the keeping of such creatures as pets. A section giving notes and news from the big public aquaria is a welcome feature newly introduced. We wish the Aquarist and Pond-keeper a long and useful life as a monthly publication.

\section{Campaign against Cancer in Algeria}

THE recent establishment of an anti-cancer organization in Algeria is of interest, in view of the particular conditions of race, custom, and climate existing in that country. Already at Algiers, attached to the surgical clinic of the hospital, a centre for treatment and investigation of cancer is in existence, with radiological equipment including a $300 \mathrm{kv}$. radiotherapeutic installation, and with the necessary laboratory services for cancer research. It is also proposed to install a larger quantity of radium for teletherapy, to set up secondary centres in the country, and to launch a scheme of propaganda against cancer.

\section{Teaching of Technical Optics}

IN the article under this title in NATURE of April 9, p. 654, in the reference made to the examinations held by the British Optical Association and the Spectacle Makers Company and to the schools recognized by the former body, it was stated that, outside London and Manchester, the attendance is "of the order of a dozen students in the session". The Principal of the Bradford Technical College writes to point out that the number of evening students taking the technical optics course at the College has in the last eight years averaged upwards of forty students, and that fifteen students have attended the full-time day course in the last five years.

\section{Co-operation between Great Britain and France}

A CORRESPONDENT, referring to principles of comity amongst nations, writes: "René A. F. de Réaumur (1683-1757), the French physicist, was elected a fellow of the Royal Society in 1738, during the presidency of Sir Hans Sloane. Later, on May 4, 1745, Réaumur, writing to Martin Folkes, then president, said: 'I heartily wish there was in the world as strong a moral attractive power as there is a natural one that might dispose our two nations particularly to seek to unite by mutual acts of friend. ship and goodwill.'"

\section{Agricultural Scholarships}

The Ministry of Agriculture and Fisheries and the Department of Agriculture for Scotland invite applications for agricultural scholarships from students who propose to follow the career of agricultural 